\title{
The Outcomes of Pregnancy with Congenital Heart Disease: An Integrative Literature Review
}

\author{
Hanan Al Obieat ${ }^{1}$, Inaam Khalaf ${ }^{1}$ (D), Maan Sh. Al Momani ${ }^{2}$ \\ ${ }^{1}$ School of Nursing, The University of Jordan, Amman, Jordan \\ ${ }^{2}$ Royal Medical Services, Queen Alia Heart Institute, Amman, Jordan \\ Email: hanandaowd@yahoo.com, khalafd@ju.edu.jo, almomany@yahoo.com
}

How to cite this paper: Al Obieat, H., Khalaf, I. and Al Momani, M.Sh. (2020) The Outcomes of Pregnancy with Congenital Heart Disease: An Integrative Literature Review. Open Journal of Nursing, 10, 473-489.

https://doi.org/10.4236/ojn.2020.105033

Received: April 9, 2020

Accepted: May 6, 2020

Published: May 9, 2020

Copyright $\odot 2020$ by author(s) and Scientific Research Publishing Inc. This work is licensed under the Creative Commons Attribution-NonCommercial International License (CC BY-NC 4.0). http://creativecommons.org/licenses/by-nc/4.0/ (c) (i) (5) Open Access

\begin{abstract}
Purpose: The purpose of this review was to identify the short-term and long-term outcomes of pregnancy in women suffering from congenital heart disease (CHD). Methods: An integrative review is used to identify the pregnancy outcomes in women with CHD. Data search was between 2010 and 2020 using Google Scholar, Scopus, Web of Science, Science Direct, Pub Med, Medline, CINAHL, EBSCO, Cochrane, and EBSCO host. Sixteen articles met the eligibility criteria. Results: The sixteen reviewed articles utilized descriptive retrospective and prospective design. Themes were short-term outcomes that include; cardiac maternal and obstetric outcomes, and long-term outcomes. Conclusion: Previous uncertainty about the ability of CHD patients to successfully become pregnant and deliver safely has replaced by the recognition that a large number can have excellent outcomes. However, these patients do continue to have higher cardiac, obstetric, and fetal risks than the general population. This illuminates the importance of preconception counseling and risk assessment for women suffering from CHD regarding the expected maternal and fetal outcomes. Moreover, there is a need for providing accurate and appropriate education about pregnancy and delivery options.
\end{abstract}

\section{Keywords}

Congenital Heart Disease, Pregnancy, Outcomes, Adverse Events

\section{Introduction}

Congenital heart disease embraces a wide range of heart defects, ranging from benign lesions such as atrial septal defects to very complex conditions, such as 
transposition of the great vessels or univentricular heart. CHD was defined as "a gross structural abnormality of the heart or intrathoracic great vessels that is actually or potentially of functional significance" [1]. The improvement in medical and surgical technologies leads to enhance the life expectancy patients with CHD dramatically during the last decades [2] [3]. Nowadays, about $90 \%$ of children who are born with heart defects can survive into adulthood [4]. As a result, adult patients suffering from CHD comprise a relatively new and constantly growing patient population [5]. Similarly, females who reach the childbearing age increased. Congenital heart diseases are the most prevalent form of heart disease among pregnant women [6] and the leading cardiac cause of maternal morbidity and mortality in developed countries [7]. Pregnancy is the most common non-cardiac cause of hospitalization among women suffering from CHD as it is associated with significant physiological changes that overwhelm the cardiovascular system [8] [9].

Traditionally, women suffering from CHD were recommended to avoid pregnancy [10]. However, recent evidence has revealed that women can get pregnant with acceptable maternal and child outcomes [10]. On the other hand, pregnancy carries many risks for women suffering from $\mathrm{CHD}$ as a result of the normal physiological changes associated with it in comparison with women without CHD or with other cardiac disorders [11]. For example, cardiac output may double immediately during the postpartum period due to the increase in heart rate and stroke volume, which results from the auto-transfusion of fluid from the contracted uterus. Increased plasma volume, decreased systemic vascular resistance, aortocaval compression, circulating catecholamines from pain, and postpartum hemorrhage are important causes of cardiac and hemodynamic stress that place these women at higher risk for adverse maternal and fetal outcomes [12]. Searching the different databases, no integrative literature review (ILR) was found that reviewed the available literature that studied pregnancy outcomes among women suffering from CHD. Accordingly, in this review, all recent and available literature that addresses these issues reviewed and integrated to get the most accurate evidence. Between the traditional perceptions of pregnancy among women suffering from CHD and the newly adapted approach regarding the risk associated with their pregnancy; there is a need to highlight the short-term and long-term outcomes that are associated with pregnancy among this population.

The results of this ILR can help in presenting synthesized evidence, in addition to adding more were information to the body of literature about pregnancy outcomes in women suffering from CHD. Moreover, having such information can help nurses and providers in providing care and education for these patients, as the identifying of outcomes of pregnancy in CHD patients will make it easier for nurses to provide an individualized care and support based on patients' expected outcomes. This ILR will increase the awareness of nursing administrators and educators about pregnancy outcomes in women suffering from CHD. 


\section{Method}

\subsection{Problem Identification}

Recently, a growing number of research that addressed pregnancy outcomes among women suffering from CHD have emerged. However, the available evidence is built mostly on reviewing patients' records in a single center with a small sample size [4]. That makes it difficult to provide meaningful advice for women suffering from CHD who wish to get pregnant. The researcher in this ILR identified the need for integrating the results of different studies to get the best available evidence regarding pregnancy outcomes among women suffering from CHD. The purpose of this integrative literature review was to examine the literature related to pregnancy outcomes among women suffering from CHD. This ILR was conducted based on Whittemore and Knafl (2005) framework. Whittemore and Knafl (2005) modified the integrative literature review method of Cooper (1998), which consists of five stages: problem formulation; a search of literature; data evaluation; data analysis; and presentation of findings [13]. This framework was considered for this review as it facilitates the inclusion of a large number of variables and considers both qualitative and quantitative evidence, with the intent to provide a broad perspective of the phenomenon [13].

\subsection{Literature Search}

In this review, the search was accomplished on January 2020 using different databases that include: Google Scholar, Scopus, Science Direct, Pub MED, Medline, CINAHL, EBSCO, Cochrane, ERIC uses the keywords of "congenital heart disease", "pregnancy", "adverse events" and "outcomes". Initially, in a separated manner from each other, then each new search added a new keyword until including all keywords. Later, these words were searched in combination with each other. The Boolean operator "OR" and "AND" were applied separately and in combination with the keywords to expand results. However, the searching process was limited to the following inclusion criteria: 1) written in English, 2) published between 2010 and 2020 to ensure a contemporary view of pregnancy outcomes, and 3) no restriction to the research design. The experimental designs, mixed-method approach, quantitative, qualitative, and descriptive studies were considered and examined to identify outcomes. However, review papers and incomplete reports in the form of editorials, opinion pieces, and conference abstracts have excluded.

\subsection{Search Results}

The principal investigator searched the literature. Two thousand and seven hundred articles were retrieved and the initial evaluation of their title abstracts took place. After evaluating and removing the duplicated articles, only 650 were found related to the topic of interest. Then, related articles were printed and read in full, following a secondary evaluation, 16 articles were exactly identified to 
cover the inclusion criteria. As a result, those sixteen articles were included in this review (see Figure 1). The principal investigator used a research matrix to extract the necessary data (see Table 1). From each article, the following data were extracted: study purpose, design, settings, sample size, and key findings. Besides, the extracted data from the articles were used another time to check eligibility of the included articles based on the early discussed eligibility criteria. Moreover, the extracted data quality was checked by the second investigator by reading all of the 16 eligible articles and confirming the data of the research matrix. All of the 16 eligible articles are quantitative.

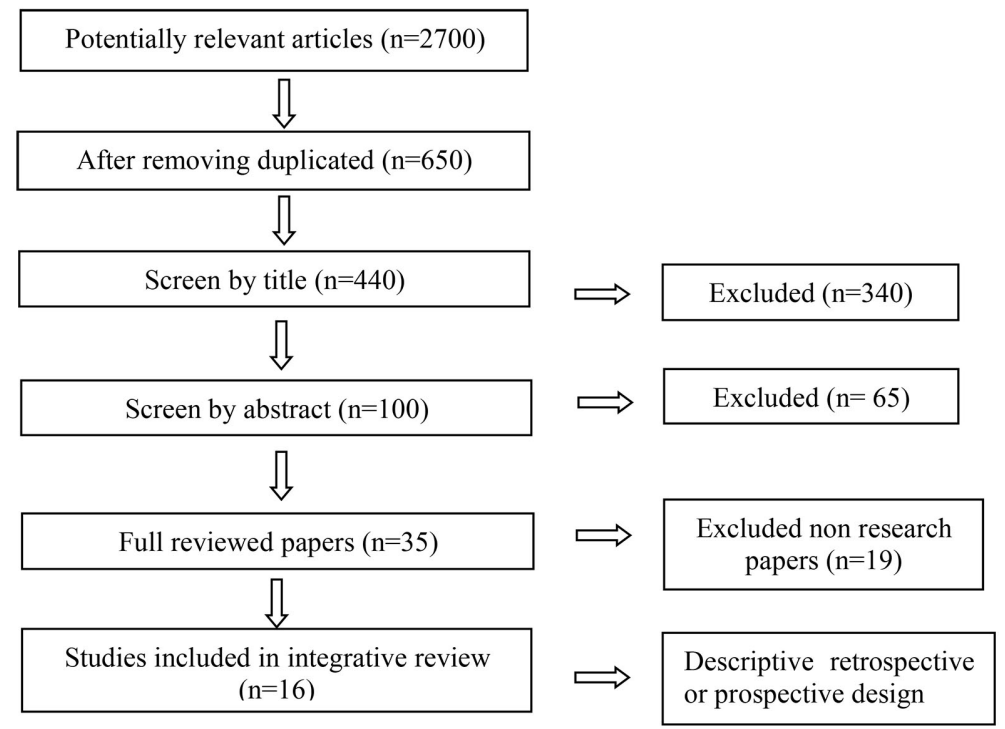

Figure 1. Flow diagram of the study selection strategy.

Table 1. Summary of the reviewed articles.

\begin{tabular}{|c|c|c|c|c|c|}
\hline Author/s & Purpose & Sample size & Settings & Design & Findings \\
\hline $\begin{array}{l}\text { Ntiloudi } \\
\text { et al., } 2017 \\
{[10]}\end{array}$ & $\begin{array}{l}\text { Highlight the } \\
\text { nature and the rate } \\
\text { of pregnancy } \\
\text { complications in a } \\
\text { single-center patient } \\
\text { population. }\end{array}$ & $\begin{array}{l}117 \text { pregnancies } \\
\text { from } 52 \mathrm{ACHD} \\
\text { patients }\end{array}$ & $\begin{array}{l}\text { AHEPA } \\
\text { University } \\
\text { Hospital, } \\
\text { Greec }\end{array}$ & $\begin{array}{l}\text { Retrospective } \\
\text { and } \\
\text { observational } \\
\text { design }\end{array}$ & $\begin{array}{l}\text { Of } 117 \text { pregnancies from } 52 \text { ACHD patients (age at } \\
\text { pregnancy } 6.6 \text { - } 28.3 \text { years), } 10 \text { were therapeutically } \\
\text { aborted. A proportion of } 41.1 \% \text { of the remaining } \\
107 \text { pregnancies were complicated either with } \\
\text { cardiac ( } 3.7 \%) \text {, obstetric ( } 15.0 \%) \text {, or fetal/neonatal } \\
\text { ( } 11.2 \%) \text { adverse events or with spontaneous } \\
\text { abortion ( } 17.8 \%) \text {. Hospitalization during pregnancy } \\
\text { was required in } 10 \text { patients. Elective cesarean } \\
\text { sections were initially planned for } 31 \% \text { of the } 87 \\
\text { pregnancies, which were finally completed, while } \\
8 \% \text { required an emergency cesarean section, mostly } \\
\text { for obstetric reasons. NYHA class deterioration } \\
\text { after pregnancy was detected in } 9.3 \% \text { of our cohort. } \\
\text { Modified WHO class III/IV, prior medication use, } \\
\text { and higher body mass index (BMI) were related to } \\
\text { cardiac complications during pregnancy or NYHA } \\
\text { deterioration. }\end{array}$ \\
\hline
\end{tabular}




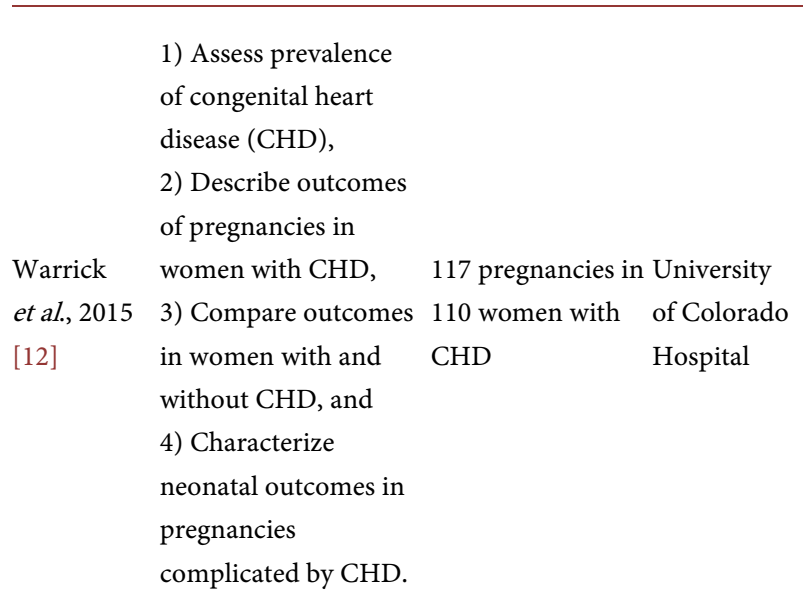

\section{Compare}

comorbidities and

adverse cardiovascular,

Schlichting obstetric, and fetal

et al., 2019 events during delivery

[19] between pregnant women with and without CHDs in the United States.
Women with and without CHDs were compared in $22,881,691$ deliveries. There were 17,729 deliveries to women with $\mathrm{CHD}$
A nationally representative sample of discharges from hospitals in the United States

\section{Determined the}

\section{national prevalence}

of GUCH parturients, A total of 39.9

Karamlou

et al., 2011

[17] their diagnostic

million births they have increased risk of peripartum complications, maternal or fetal death.
We identified 117 pregnancies in 110 women with CHD. Parturient with CHD were more likely to have operative vaginal delivery $(\mathrm{P}=0.0001)$, neonatal ICU admissions $(\mathrm{P}=0.003)$, and had prolonged hospital stays. Occurrence of $\mathrm{CHD}$ in neonates was $6 \%$. Moderate-to-severe valvular
Retrospective cohort study

Stratified, cross-sectional observational design disease was associated with increased rates of operative vaginal delivery, early initiation of neuraxial labor analgesia, cardiac complications (including arrhythmia and use of diuretics), prolonged hospital stay, and maternal ICU admission. However most deliveries and births were uncomplicated; and there were one case each of maternal mortality and fetal death after birth.

There were approximately 22,881,691 deliveries in the United States between 2008 and 2013. Among the delivery hospitalizations, 17,729 were to women with CHDs, Women with CHD had higher comorbidities in comparison with women without CHDs. cardiac events including heart failure, arrhythmia, and thromboembolic events were significantly greater among pregnant women with CHDs than pregnant women without. Women with CHDs are at an increased risk for numerous cardiovascular, obstetric, and fetal events at the time of delivery. The odds of an adverse maternal cardiac event during delivery were 2.4 to 27.6 times higher for women with CHDs compared with women without. Among the cardiac events examined, the odds of heart failure during delivery were the highest, Women with CHDs also showed significantly increased odds of other adverse obstetric events, including pre-term delivery, hemorrhage, and placental abruption.

Infants born to mothers with CHDs were more likely to possess birth defects or exhibit growth restriction at birth, but less likely to experience fetal distress. These infants may experience growth restriction.

The GUCH parturients, especially those with VSD, have increased risk of mortality and peripartum complications compared with other age-matched women.

The GUCH women had a significantly higher prevalence of all peripartum complications studied compared with non-GUCH women, including preterm delivery ( $10.2 \%$ vs $7.2 \%$ ), induction ( $35.6 \%$ vs $32.5 \%$ ), surgically assisted delivery ( $11.8 \%$ vs $7.9 \%)$, and caesarean birth (33.6\% vs $27.2 \%)$ ( $p=0.001$ for all). Hospital length of stay was similar for both GUCH and non GUCH women and was 2.5 days. 


\section{Continued}

\begin{tabular}{|c|c|c|c|c|c|}
\hline $\begin{array}{l}\text { Ramage } \\
\text { et al., } 2019 \\
{[16]}\end{array}$ & $\begin{array}{l}\text { To assess the } \\
\text { association of ACHD } \\
\text { and its subtypes with } \\
\text { pregnancy, maternal, } \\
\text { and neonatal } \\
\text { outcomes. }\end{array}$ & $\begin{array}{l}2114 \text { women with } \\
\text { ACHD }\end{array}$ & $\begin{array}{l}\text { Population-level } \\
\text { administrative } \\
\text { data from the } \\
\text { Discharge } \\
\text { Abstract } \\
\text { Database (DAD) } \\
\text { in Canada }\end{array}$ & $\begin{array}{l}\text { Cross-sectional } \\
\text { retrospective } \\
\text { design }\end{array}$ & $\begin{array}{l}\text { In this large cross-sectional study of } 2114 \text { women with } \\
\text { adult congenital heart disease in Canada, maternal and } \\
\text { neonatal outcomes varied by subtype of maternal heart } \\
\text { condition. Adult congenital heart disease was associated } \\
\text { with increased odds of adverse maternal, neonatal, and } \\
\text { pregnancy outcomes during labor and delivery } \\
\text { hospitalization. }\end{array}$ \\
\hline
\end{tabular}

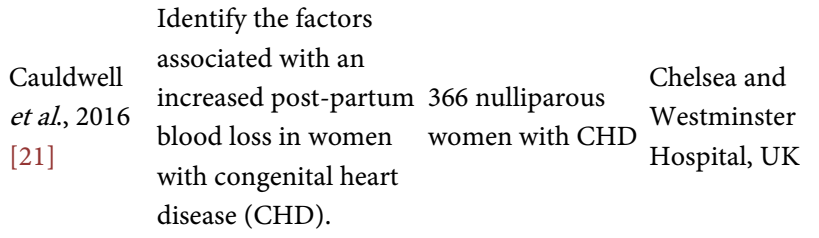

To study pregnancy

Yadav et al., outcomes in operated

2018 vs non-operated cases

[19] of congenital heart

disease cases during pregnancy.

55 patients of

CHD, 29 women Obstetric unit of

had no cardiac a tertiary center Retrospective surgery and 26 had unit, India cardiac surgery
1) Assess functional class during and after pregnancy.

Gußmann

et al., 2013

[28]

\section{Analysis a}

self-assessment of

health, work capability

and physical activity

during the longest

recorded possible

follow-up period.
1) Characterize the risk factors for pregnancy-associated Kamiya, cardiac events, and et al., 2012 2) to evaluate the

[15] long-term effects of pregnancy on the heart in women with repaired TOF.
Retrospective study. The long-term data

German

Heart Centre were acquired with a

Berlin, Germany self-assessment questionnaire from each patient

40 deliveries in 25 patients with repaired TOF
National

Cerebral and

Cardiovascular

Center, Japan
Women with $\mathrm{CHD}$ are at increased risk of post-partum hemorrhage (PPH).

Only women with a Fontan circulation were still A retrospective significantly associated with higher blood loss at study design delivery.

Data support vaginal delivery as the default for women with cardiac disease. As it is associated with a lower risk of post-partum hemorrhage and a better fetal outcome.

There was no difference in cardiac complications, NYHA deterioration and need of cardiac drugs in the two groups. Obstetric complications and mode of delivery were also similar in the two groups. Birth weight was also similar in the both groups. Stillbirth rate and other neonatal complications were also similar in two groups.

Evaluate the short-term and long-term follow-up in simpler and more complex cardiac defects

The short-term outcome data for obstetric, maternal cardiac and neonatal complications. Outcome data on maternal cardiac complications indicated that two-thirds of the patients had no cardiovascular events. The main cardiac symptom was the loss of functional class before and in pregnancy. Prematurity and small sizes for gestational age were the main neonatal complications.

Two-thirds of the patients reported good outcomes in the self-assessments of health, work capability and physical activity in the long-term follow-up period. The health self-assessment correlated with physical activity. For the long-term outcomes, $18 \%$ of the patients with contraindications died.

Only $25 \%$ of these patients answered the questionnaire. All of these patients suffered from pulmonary hypertension.

Cardiac Events occurred in 7 of 40 deliveries (17.5\%) in 7 patients (28\%): 1 case of new onset of non-sustained ventricular tachycardia (NSVT) requiring treatment, 2 of heart failure, and 4 of worsening heart failure and arrhythmias including SVT and NSVT.

Retrospective Obstetric Events: The mean week of delivery was descriptive study shorter in patients with cardiac events than in those without cardiac events.

Offspring Events: There were no neonatal deaths. The mean birth weight was $2665 \mathrm{~g}$ and was significantly lower for offspring of patients with cardiac events. The predictors of maternal cardiac events were a history of ablation for SVT and large CTR on chest radiograph. 


\begin{tabular}{|c|c|c|c|c|c|}
\hline $\begin{array}{l}\text { Kampman } \\
\text { et al., } 2015 \\
{[27]}\end{array}$ & $\begin{array}{l}\text { To observe the } \\
\text { incidence of } \\
\text { cardiovascular } \\
\text { complications in the first } \\
\text { year postpartum and to } \\
\text { compare cardiac function } \\
\text { parameters } \\
\text { pre-pregnancy and } \\
\text { 1-year postpartum in } \\
\text { women with CHD. }\end{array}$ & $\begin{array}{l}172 \text { pregnancies } \\
\text { in } 172 \text { women }\end{array}$ & $\begin{array}{l}8 \text { participating } \\
\text { centers, the } \\
\text { Netherlands }\end{array}$ & $\begin{array}{l}\text { A prospective } \\
\text { multicenter } \\
\text { cohort study }\end{array}$ & $\begin{array}{l}\text { Cardiovascular events 1-year postpartum: } \\
\text { Women with higher modified WHO risk classifications } \\
\text { before pregnancy had higher cardiovascular events. Of } \\
\text { the women with cardiovascular events postpartum, } \\
63.6 \% \text { had no history of cardiovascular events before } \\
\text { pregnancy and } 71.4 \% \text { developed new arrhythmia. } \\
\text { Women with cardiovascular events during pregnancy } \\
\text { had a higher risk of cardiovascular events postpartum } \\
\text { compared with women without cardiovascular events } \\
\text { during pregnancy. The incidence of cardiovascular } \\
\text { events 1-year postpartum was } 6.4 \% \text {. }\end{array}$ \\
\hline $\begin{array}{l}\text { Pillutla } \\
\text { et al., } 2016 \\
{[18]}\end{array}$ & $\begin{array}{l}\text { To identify the } \\
\text { cardiovascular and } \\
\text { neonatal outcomes in } \\
\text { pregnant women with } \\
\text { high-risk CHD. }\end{array}$ & $\begin{array}{l}61 \text { pregnancies } \\
\text { in } 43 \text { women }\end{array}$ & $\begin{array}{l}\text { The } \\
\text { Ahmanson/ } \\
\text { University of } \\
\text { California Los } \\
\text { Angeles (UCLA) } \\
\text { Adult } \\
\text { Congenital } \\
\text { Heart Disease } \\
\text { Center } \\
\text { (ACHDC), USA }\end{array}$ & $\begin{array}{l}\text { Single-center } \\
\text { retrospective } \\
\text { analysis }\end{array}$ & $\begin{array}{l}\text { Of all pregnancies, } 31 \% \text { were complicated by a } \\
\text { cardiovascular event and that the most common cardiac } \\
\text { events were either heart failure or arrhythmias. } \\
\text { Development of any major cardiac complication during } \\
\text { pregnancy was best predicted by antepartum maternal } \\
\text { arrhythmia. }\end{array}$ \\
\hline $\begin{array}{l}\text { Bowater } \\
\text { et al., } 2013 \\
{[25]}\end{array}$ & $\begin{array}{l}\text { To examined whether the } \\
\text { deterioration associated } \\
\text { with pregnancy is due to } \\
\text { the physiological changes } \\
\text { of pregnancy itself, or is } \\
\text { part of the known } \\
\text { deterioration that } \\
\text { occurs with time in these } \\
\text { patients. }\end{array}$ & $\begin{array}{l}31 \text { pregnancies } \\
\text { in } 18 \text { women }\end{array}$ & $\begin{array}{l}\text { Queen Elizabeth } \\
\text { Hospital, UK }\end{array}$ & $\begin{array}{l}\text { Retrospective } \\
\text { analysis }\end{array}$ & $\begin{array}{l}\text { This study suggests that pregnancy is associated with a } \\
\text { premature deterioration in RV function in women with } \\
\text { a systemic RV. These women are also more } \\
\text { symptomatic, with a greater reduction in functional } \\
\text { class compared with patients with a systemic RV who } \\
\text { do not undergo pregnancy. } \\
\text { There are increased risks in comparison with the } \\
\text { general population, with a higher preterm delivery and } \\
\text { low birth weight rates. There is also a higher cesarean } \\
\text { section rate in this population, } 39 \% \text { vs. a } 23 \% \text { average } \\
\text { for the hospital. }\end{array}$ \\
\hline $\begin{array}{l}\text { Assenza } \\
\text { et al., } 2013 \\
{[24]}\end{array}$ & $\begin{array}{l}\text { To better understand the } \\
\text { quantitative volumetric } \\
\text { changes associated with } \\
\text { pregnancy in women } \\
\text { with repaired tetralogy of } \\
\text { Fallot (TOF), utilizing } \\
\text { sequential cardiovascular } \\
\text { magnetic resonance } \\
\text { (CMR) imaging. }\end{array}$ & $\begin{array}{l}30 \text { pregnancies } \\
\text { in } 30 \text { women, } \\
\text { and } 26 \\
\text { nulliparous } \\
\text { women } \\
\text { (Total 56) }\end{array}$ & $\begin{array}{l}\text { Boston } \\
\text { Children's } \\
\text { Hospital, USA }\end{array}$ & $\begin{array}{l}\text { Retrospective } \\
\text { analysis of } \\
\text { records }\end{array}$ & $\begin{array}{l}\text { Women with repaired TOF who have completed } \\
\text { pregnancy appear to experience an accelerated rate of } \\
\text { right ventricular remodeling, defined as an increase in } \\
\text { end-diastolic volume; however RV systolic function } \\
\text { does not deteriorate. }\end{array}$ \\
\hline $\begin{array}{l}\text { Ladouceur } \\
\text { et al., } 2016 \\
{[22]}\end{array}$ & $\begin{array}{l}\text { To describe maternal and } \\
\text { fetal outcomes during } \\
\text { pregnancy in patients } \\
\text { with PAH-CHD. }\end{array}$ & $\begin{array}{l}28 \text { pregnancies } \\
\text { in } 20 \text { women }\end{array}$ & $\begin{array}{l}\text { Seven different } \\
\text { French centers, } \\
\text { France }\end{array}$ & $\begin{array}{l}\text { Retrospective } \\
\text { multi-center } \\
\text { analysis }\end{array}$ & $\begin{array}{l}28 \text { pregnancies in } 20 \text { women ( } 26 \pm 6 \text { years old) with } \\
\text { PAH-CHD were managed during this period. There } \\
\text { were } 18 \text { complete pregnancies ( } \geq 20 \text { weeks' gestation } \\
(\text { WG)), } 8 \text { abortions and } 2 \text { miscarriages. Six }(33 \%) \\
\text { patients experienced severe cardiac events they had } \\
\text { lower resting oxygen saturation. The most common } \\
\text { cardiac complications during the complete pregnancies } \\
\text { were heart failure ( } n=4) \text { and severe hypoxemia }(n=5) \text {. } \\
\text { Heart failure was overall severe, requiring inotropic } \\
\text { treatment in three patients, mechanical circulatory } \\
\text { support in one and led to one maternal death (mortality } \\
=5.0 \%) \text {. Obstetrical complications occurred in } 25 \% \text { of } \\
\text { pregnancies. Small for gestational age was diagnosed in } \\
39 \%(7 / 18) \text { of fetuses. } 12 / 18(67 \%) \text { pregnancies were } \\
\text { delivered by caesarean section, of which } 10 \text { in } \\
\text { emergency for obstetrical reason. Prematurity was } \\
\text { frequent }(78 \%) \text {, but no neonatal death occurred. }\end{array}$ \\
\hline
\end{tabular}




\begin{tabular}{|c|c|c|c|c|}
\hline \multirow{6}{*}{$\begin{array}{l}\text { Silversides } \\
\text { et al., } 2018 \\
\text { [23] }\end{array}$} & \multirow{5}{*}{$\begin{array}{l}\text { 1) Examine cardiac } \\
\text { complications during } \\
\text { pregnancy and their } \\
\text { temporal trends; and } \\
\text { 2) Derive a risk }\end{array}$} & \multirow{4}{*}{$\begin{array}{l}1938 \text { pregnancies } \\
\text { were included }\end{array}$} & \multicolumn{2}{|l|}{2 large Canadian } \\
\hline & & & tertiary care & \\
\hline & & & hospitals. & \\
\hline & & & (Toronto and & desion \\
\hline & & & Vancouver) & \\
\hline & stratification index. & & Canada & \\
\hline
\end{tabular}

To examine the

Balint $e t$ al, frequency and

2010 determinants of late

cardiac events (LCE)

in a large cohort of

405 pregnancies in

A tertiary care Prospective

318 women

women with CHD.
Cardiac complications occurred in 16\% of pregnancies and were primarily related to arrhythmias and heart failure. Although the overall rates of cardiac complications during pregnancy did not change over the years, the frequency of pulmonary edema decreased. Ten predictors of maternal cardiac complications were identified: 5 general predictors (prior cardiac events or arrhythmias, poor functional class or cyanosis, high-risk valve disease/left ventricular outflow tract obstruction, systemic ventricular dysfunction, no prior cardiac interventions); 4 lesion-specific predictors (mechanical valves, high-risk aortopathies, pulmonary hypertension, coronary artery disease); and 1 delivery of care predictor (late pregnancy assessment). These 10 predictors were incorporated into a new risk index (CARPREG II [Cardiac Disease in Pregnancy Study]). The median follow-up time was 2.6 years after pregnancy. LCE occurred after $12 \%$ (50/405) of pregnancies. The 5-year rate of LCE was higher in women with adverse cardiac events during pregnancy than in those without. Women at highest risk for LCE were those with functional limitations, cyanosis, ventricular dysfunction and left ventricular outflow tract obstruction. Three women $(0.007 \%)$ died after pregnancy. The most common LCEs were arrhythmias which occurred in 35 women. Sixty-two pregnancies (15\%) were followed by therapeutic cardiac interventions; the most common indications for intervention were arrhythmia and/or congestive heart failure $(40 \%)$ or deterioration in functional capacity (38\%). Approximately $1 / 10$ pregnancies were followed by a LCE.

\subsection{Data Evaluation, Rigor, and Data Quality}

The quality of methods used in the included articles was assessed by using criteria for assessing the quality of quantitative studies, which was recommended by Kmet et al. (2014). The checklist comprised of 14 questions with a corresponding scoring system as follows: (Yes $=2)$; (Partially $=1)$; $(\mathrm{No}=0)$; and not applicable [14]. The manual provided comprehensive instructions for scoring each aspect. The quality of each article was then rated as being strong $(>80 \%)$, good $(70 \%$ $80 \%)$, adequate $(50 \%-69 \%)$ or limited $(<50 \%)$ [14].

The quality score of each article was calculated by summing the total score of items and dividing it by the highest possible total score after removing non-applicable items. The calculated summary score for each article can range between zero and two (see Table 2). This assessment was independently attained by two reviewers to determine the strengths and weaknesses of the studies and any discrepancies in opinion were resolved through discussion (Kmet et al., 2004). 


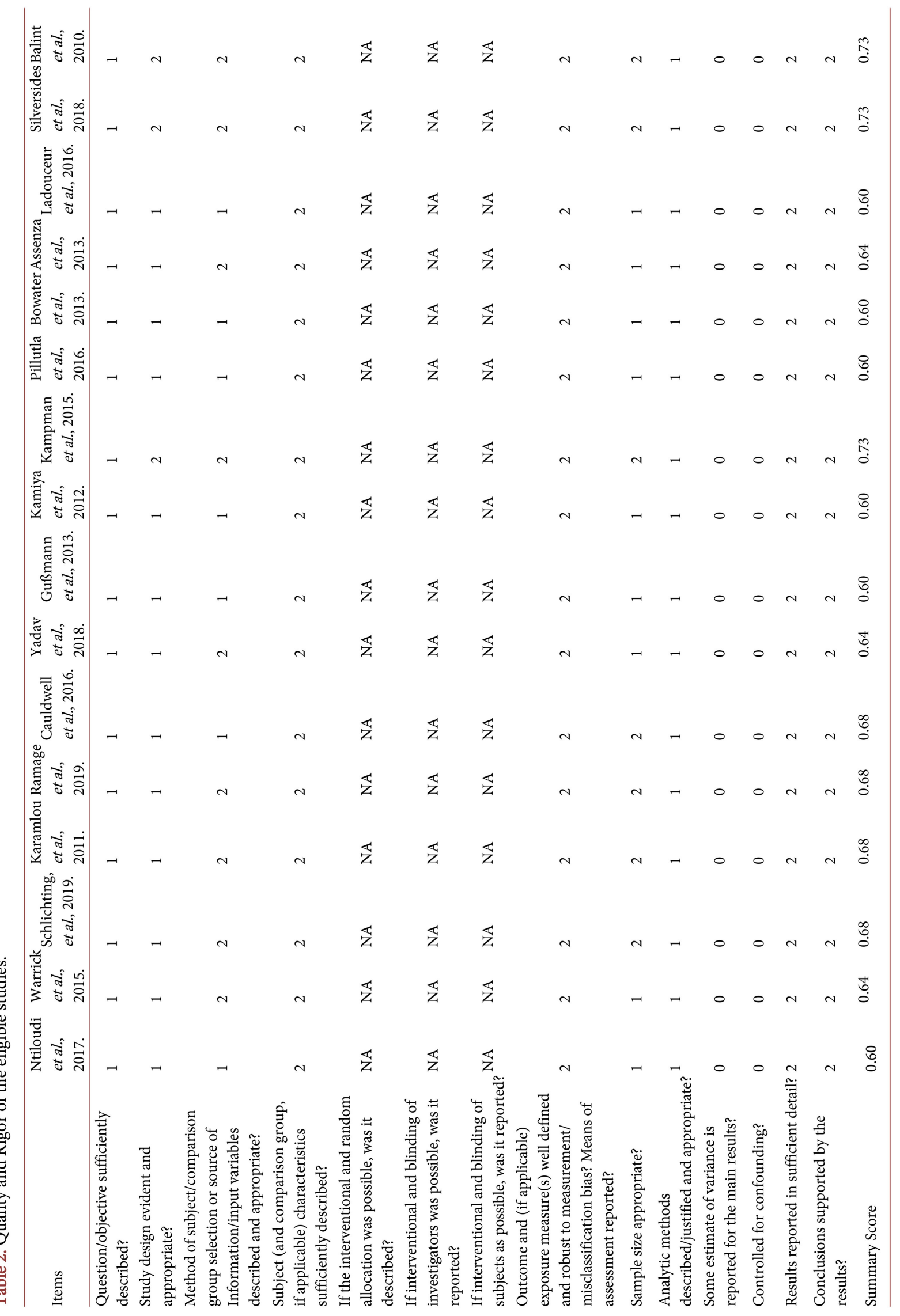




\subsection{Data Analysis}

Following Whittemore and Knafl's (2005) methodological approach of conducting an integrative review, analysis has four phases. 1) Data reduction: represents a process that divides the primary sources into subgroups to facilitate analysis. 2) Data display: showing data as they appeared in the research matrix (data extraction sheet), to enhance comparison. 3) Data comparison: examining data to identify patterns, relationships, and themes, by which variables can be grouped together and a conceptual map can be drawn. 4) Conclusion drawing and verification: conclusion drawing occurs when the inquirer identifies patterns and relationships at a more abstract level, and generalizes the findings to populations of interest [13].

\section{Results}

The reviewed articles showed that women suffering from CHD can get pregnancy safely without any adverse events [10] [12] [15] [16]; however, there are still some associated risks that could affect the mother and the offspring negatively. The occurrence of such adverse events mainly depends on the severity of CHD and the residual lesions [16]. The pregnancy outcomes were addressed by time into short-term outcomes and long-term outcomes.

\subsection{Short-Term Outcomes}

In the reviewed studies, pregnancy in women with CHD showed a satisfactory outcomes for both of the mothers and the fetus [10] [12] [16] [17] [18] [19]. However, there are still some complications that take place which is higher in this population than women without CHD [20]. The occurrence and severity of these complications and adverse outcomes depend mainly on the complexity of the lesions (Warrick et al., 2015). The reported short-term outcomes are divided into three major categories: maternal/obstetric, fetal, and cardiac outcomes.

\subsubsection{Maternal/Obstetric Outcomes}

Congenital heart diseases not only pose a cardiac impact on women, but it has obstetric impacts, too. Many adverse obstetric outcomes were reported in the literature; such as pregnancy-induced hypertension (PIH: systolic blood pressure (BP) $\geq 140 \mathrm{~mm} \mathrm{Hg}$ or diastolic BP $\geq 90 \mathrm{~mm} \mathrm{Hg}$ after 20 weeks of gestation), premature labor (labor before 37 weeks of gestation), DVT/PE, placenta previa, placenta abruption and postpartum hemorrhage ( $\mathrm{PPH}$ ) (blood loss in vaginal delivery $\geq 800 \mathrm{ml}$ or in cesarean delivery (CS) $\geq 1,500 \mathrm{ml}$ ) [10] [12] [20]. However, the placental disease was not different significantly between women with and without CHD (Schlichting et al., 2019). In some subtypes of CHD, women with CHD had significantly lower probabilities of placental disease as paralleled with the general population [16]. Moreover, prolong hospitalization and increase utilization of the services were reported, especially with complex CHD [12] [20]. A diagnosis of the ventricular septal defect (VSD) was associated with a signifi- 
cantly higher prevalence of maternal mortality and morbidity than the other CHD subtypes ( $p=0.01)$ [16] [17] [21].

Postpartum hemorrhage occurs overall at a rate of $21 \%$ in CHD [21]. Vaginal delivery was found as a preferable mode of delivery considering the maternal risk to reduce the risk of $(\mathrm{PPH})$ [21]. Furthermore, the forceps delivery; anticoagulant medication; the complexity of $\mathrm{CHD}$ and Fontan circulation were identified as a predictor of $\mathrm{PPH}$ [21].

Ladouceur et al. (2017) recently assessed obstetric and fetal outcomes of 28 pregnancies among 20 women suffering from pulmonary arterial hypertension associated with congenital heart disease. Overall, $33 \%$ of pregnancies were associated with adverse cardiac events with a severe reduction in resting oxygen saturation [22]. Obstetrical adverse events occurred in (25\%) of the pregnancies, such as postpartum hemorrhage occurred in four cases, premature rupture of membranes in one case. Small for gestational age, was diagnosed in $39 \%$ of fetuses. Of the study participants, $67 \%$ of pregnancies were delivered by cesarean section, of which 10 participants were in an emergency for an obstetrical reason. Prematurity was frequent (78\%), but no neonatal death occurred [22].

\subsubsection{Fetal Outcomes}

The risk of fetal and neonatal complications is higher among pregnant women with CHD as compared to healthy women [16] [17] [20]. The presence of maternal cardiovascular disease can place the fetus and neonate at greater risk [20]. The type and severity of neonatal complications are determined by the type and severity of the maternal underlying cardiac conditions and subtype [16]. For example, preterm birth incidence ranged from $9.7 \%$ in women with ventricular septal defects to $27.2 \%$ in women with a single ventricle [16]. One mechanism that has been suggested as a source for these complications is insufficient uteroplacental blood flow in the setting of cardiac anomalies resulting in a slowing of fetal growth, making premature termination of pregnancy necessary or leading to spontaneous abortion [22]. Adverse fetal and neonatal outcomes complicate $11.5 \%$ - 39\% of pregnancies [17] [20] [22]. Fetal adverse events were identified as small-for-gestational-age (SGA, birth weight $<10$ th percentile), complications with congenital heart disease, prematurity, and intrauterine or neonatal death (within 28 days). These complications could occur in any form of $\mathrm{CHD}$ even if it is repaired or not [19]. One study documented overall fetal mortality of $1 \%$ and a fetal deformity rate of $18 \%$ [20]. Prematurity and low gestational ages were the main complications in pulmonary artery hypertension and it is increasing in severity as the resting oxygen saturation decreased [22]. The risk for a woman with CHD to have a child who also has a congenital heart defect depends on and varies based on the type of maternal heart disease ranging from $3 \%$ to $12 \%$. For defects with an autosomal dominant transmission pattern (such as Marfan syndrome), the risk increased by up to $50 \%$. In such cases, genetic screening should be obtained in the 12th week of pregnancy [20]. 


\subsubsection{Cardiac Outcomes}

Cardiac events were reported as new onset or worsening of arrhythmia requiring treatment, heart failure which is diagnosed through the following criteria (a decline in New York Heart Association (NYHA) class, pulmonary congestion confirmed by chest radiography, the requirement for diuretic therapy), endocarditis, or thromboembolic events during pregnancy to one month after delivery [15]. Adverse maternal cardiac events after pregnancy were more common in women who had cardiac events during pregnancy [12] [23]. Moreover, Assenza and colleagues (2013) conducted a retrospective analysis to better understand the effect of pregnancy on right ventricular remodeling in women with repaired TOF, and they found that pregnancy accelerates the rate of right ventricular remodeling in pregnancy group compared with the non-pregnancy group, which means an increase in end-diastolic volume; however, the RV systolic function does not decline [24] [25].

Arrhythmia and heart failure are the most commonly occurring cardiac adverse event during pregnancy [18] [23]. A pre-conception evaluation and history of SVT or the use of any cardiac medications should be assessed to predict the cardiac risks and outcomes. The presence of pre-pregnancy arrhythmias is considered a predictor of major cardiac events during pregnancy [18]. In a prospective study to evaluate the pregnancy outcomes in women with heart disease, ten predictors were identified. Which were: five general predictors (prior cardiac events or arrhythmias, poor functional class or cyanosis, high-risk valve disease/left ventricular outflow tract obstruction, systemic ventricular dysfunction, no prior cardiac interventions); four lesion-specific predictors (mechanical valves, high-risk aortopathies, pulmonary hypertension, coronary artery disease); and the last predictor is the delivery of care (late pregnancy assessment) [23].

In a contradictory to the traditional thinking that pregnancy outcomes will be better in women with CHD who underwent a cardiac repair surgery; Yadav and his colleagues (2018) found no statistically significant differences in the cardiac, maternal and neonatal outcomes between the operated CHD and non-operated CHD population who pose the same baseline characteristics [19]. Also, they recommend that every woman with CHD should do a pre-pregnancy risk assessment and consultation to obtain optimum care [19].

\subsection{Long-Term Outcomes}

Limited studies have assessed the effect of pregnancy on long-term outcomes in women suffering from CHD. To assess the cardiac outcomes in women suffering from CHD after pregnancy, Balint and colleagues (2010) conducted a prospective study recruiting a consecutive sample of pregnant women who were referred for follow up or consultation in a cardiac center. The data were collected throughout 1995-2007, antenatal, perinatal and postnatal data were collected from these pregnant women. At the first antenatal visit, comprehensive examinations and investigations to assess the cardiac conditions were performed as baseline data. Also, during pregnancy; any cardiac complications were recorded, and any ob- 
stetric or fetal complications were recorded too; to be studied as predictors with any late cardiac complications after pregnancy completion. The late cardiac complications were defined as: sudden cardiac death, pulmonary edema, cardiac arrhythmias (Tachy/Bradyarrhythmias), stroke or transient ischemic attacks [26]. This study involved 405 pregnancies. Of them, 50 (12\%) had late cardiac events; three women died after pregnancy. This incidence is higher than reported by Kampman et al. (2015) in their prospective multicenter study. The most occurred complication was cardiac arrhythmias; it occurred in thirty-five women. The most frequent arrhythmia was supraventricular tachycardia followed by atrial fibrillation. Also, fifteen women developed congestive heart failure [26]. In this study, about 1/10 women have gotten late cardiac events. The women with poor baseline functional ability and/or cyanosis, ventricular dysfunction and left ventricular outflow tract obstruction were at the highest risk for late cardiac complications. In addition, women who developed cardiac complications during pregnancy were at higher risk of getting late cardiac complications after delivery. It is crucial to take into consideration these factors as predictors for late cardiac complications post-delivery among high-risk women during pre-pregnancy counseling and assessment [26].

To follow the long-term outcomes one-year post-delivery, Kampman et al. (2015) conducted a prospective multi-center cohort study. They found that the complications after one year of delivery are rare; the overall incidence rate was $6.4 \%$. The occurrence of post-partum complications was higher in women with a mechanical prosthetic valve, in women who use cardiac medications, pre-pregnancy, especially beta-blockers and anti-coagulants, and in women with a history of arrhythmias [27].

Gußmann et al. (2013) conducted an analysis of a self-assessment of health, work capability, and physical activity during the longest possible follow-up period; the follow-up period reached up to eleven years. In this analysis, 107 women were followed, two-thirds of the patients reported good outcomes in the self-assessments of health, work capability and physical activity in the long-term follow-up period. The health self-assessment correlated positively with the physical activity. For the long-term outcomes, eighteen percent of the women with contraindications to pregnancy died, and all patients (with contraindications to pregnancy) who responded to the follow up questionnaire developed pulmonary hypertension. The results of this study suggest to continue in the advisement of contradictory of pregnancy considering not only the short-term outcomes, but also the long-term outcomes [28].

\section{Discussion}

In this review, the following themes were identified: short-term outcomes that are divided into three sub-categories: maternal, cardiac, and fetal outcomes [10] [15]-[24] and long-term outcomes [25] [26] [27] [28]. Based on interpretation and synthesis of the reviewed articles the following results can be demonstrated; 
women with CHD can tolerate pregnancy with satisfactory maternal and fetal outcomes. However, they still have an increased risk of cardiac and fetal complications than the ordinary population. The overall incidence of CHD among pregnant women was $0.6 \%$ [12].

The calculated scores for the rigor of the research articles ranged between 0.60 and 0.73 , with a mean average of 0.65 . In addition, the minimum score of the included studies was 0.60 indicating adequate rigor of the included studies; therefore, no studies were excluded based on the calculated scores.

There are some limitations of the reviewed articles. Out of the 16 reviewed articles, thirteen research articles were conducted in a retrospective manner over a variable period. Of them, eleven had taken place in a single center or hospital to evaluate the cardiac and fetal outcomes for women suffering from CHD [10] [15]-[24]. While the remaining three articles were conducted prospectively, two of them were conducted in multi-center settings. Mostly, these studies have given us almost consistent results regarding the maternal and fetal outcomes among CHD patients. Reviewing the patients' records retrospectively could be beneficial for recognizing maternal and fetal outcomes, however; it is not the most robust design to identify these outcomes. Regarding the sample size, only three research results were concluded based on a national representative sample or a population-based sample [16] [17] [20]. Additionally, the sample size was small in most of the reviewed articles, which may relate to the nature of the studied population and the availability of the cases; this is in some degree limits the generalizability of the findings.

As most of the reviewed articles are conducted in retrospective or so-called survivor cohorts, there is a need for using more robust designs to get more valid results. Moreover, for accurate estimations of serious and relatively rare complications a large-scale (multicenter and international) prospective registration remains needed.

Several limitations of the present ILR need to be discussed. The quality of the review depends on the design of the articles included. The study designs mostly based on reviewing the patients' records retrospectively, and few prospective studies to follow the long-term outcomes; therefore, the results need to be judged with caution. Selection bias is introduced by excluding articles based on the earlier-mentioned criteria. Underreporting of complications may also be an important problem.

\section{Conclusion}

The last decades show a progressive advancement in the management of congenital heart disease; that results in large numbers of women with repaired CHD, who are able now to successfully become pregnant and deliver healthy offspring. Previous uncertainty about the ability of these patients to successfully become pregnant and deliver safely has been replaced by the recognition that a large number can have excellent outcomes. However, despite this, these patients do 
continue to have higher cardiac, obstetric, and fetal risks than the general population. This highlights the importance of preconception counseling regarding the increased risk of fetal congenital heart disease with affected mothers and referrals for genetic assessment and counseling where appropriate, moreover, providing the appropriate and accurate advice for women about the potential adverse events that they may encounter on short-term and long-term basis.

\section{Conflicts of Interest}

The authors declare no conflicts of interest regarding the publication of this paper.

\section{References}

[1] Mitchell, S., Korones, S. and Berendes, H. (1971) Congenital Heart Disease in 56,109 Births Incidence and Natural History. Circulation, 43, 323-332. https://doi.org/10.1161/01.CIR.43.3.323

[2] Hoffman, J.I. and Kaplan, S. (2002) The Incidence of Congenital Heart Disease. Journal of the American College of Cardiology, 39, 1890-1900. https://doi.org/10.1016/S0735-1097(02)01886-7

[3] van der Bom, T., Bouma, B.J., Meijboom, F.J., Zwinderman, A.H. and Mulder, B.J. (2012) The Prevalence of Adult Congenital Heart Disease, Results from a Systematic Review and Evidence Based Calculation. American Heart Journal, 164, 568-575. https://doi.org/10.1016/j.ahj.2012.07.023

[4] Stout, K.K., Daniels, C.J., Aboulhosn, J.A., Bozkurt, B., Broberg, C.S. and Colman, J.M. (2019) 2018 AHA/ACC Guideline for the Management of Adults with Congenital Heart Disease: A Report of the American College of Cardiology/American Heart Association Task Force on Clinical Practice Guidelines. Journal of the American College of Cardiology, 73, e81-e192. https://doi.org/10.1161/CIR.0000000000000602

[5] Ávila, P., Mercier, L.-A., Dore, A., Marcotte, F., Mongeon, F.-P. and Ibrahim, R. (2014) Adult Congenital Heart Disease: A Growing Epidemic. Canadian Journal of Cardiology, 30, S410-S419. https://doi.org/10.1016/j.cjca.2014.07.749

[6] Drenthen, W., Pieper, P.G., Roos-Hesselink, J.W., van Lottum, W.A., Voors, A.A. and Mulder, B.J. (2007) Outcome of Pregnancy in Women with Congenital Heart Disease: A Literature Review. Journal of the American College of Cardiology, 49, 2303-2311. https://doi.org/10.1016/j.jacc.2007.03.027

[7] Warnes, C.A. (2015) Pregnancy and Delivery in Women with Congenital Heart Disease. Circulation Journal, CJ-15-0572. https://doi.org/10.1253/circj.CJ-15-0572

[8] Opotowsky, A.R., Siddiqi, O.K. and Webb, G.D. (2009) Trends in Hospitalizations for Adults with Congenital Heart Disease in the US. Journal of the American College of Cardiology, 54, 460-467. https://doi.org/10.1016/j.jacc.2009.04.037

[9] Verheugt, C.L., Uiterwaal, C.S., van der Velde, E.T., Meijboom, F.J., Pieper, P.G. and Sieswerda, G.T. (2010) The Emerging Burden of Hospital Admissions of Adults with Congenital Heart Disease. Heart, 96, 872-878. https://doi.org/10.1136/hrt.2009.185595

[10] Ntiloudi, D., Zegkos, T., Bazmpani, M.A., Parcharidou, D., Panagiotidis, T. and Hadjimiltiades, S. (2018) Pregnancy Outcome in Women with Congenital Heart Disease: A Single-Center Experience. Hellenic Journal of Cardiology, 59, 155-159. 
https://doi.org/10.1016/j.hjc.2017.08.008

[11] Ananaba, I., Hare, J. and Franklin, W. (2011) The Pregnant Patient with Congenital Heart Disease. Methodist DeBakey Cardiovascular Journal, 7, 9-12. https://doi.org/10.14797/mdcj-7-2-9

[12] Warrick, C.M., Hart, J.E., Lynch, A.M., Hawkins, J.A. and Bucklin, B.A. (2015) Prevalence and Descriptive Analysis of Congenital Heart Disease in Parturients: Obstetric, Neonatal, and Anesthetic Outcomes. Journal of Clinical Anesthesia, 27, 492-498. https://doi.org/10.1016/j.jclinane.2015.04.006

[13] Whittemore, R. and Knafl, K. (2005) The Integrative Review: Updated Methodology. Journal of Advanced Nursing, 52, 546-553. https://doi.org/10.1111/j.1365-2648.2005.03621.x

[14] Kmet, L.M., Cook, L.S. and Lee, R.C. (2004) Standard Quality Assessment Criteria for Evaluating Primary Research Papers from a Variety of Fields.

[15] Kamiya, C.A., Iwamiya, T., Neki, R., Katsuragi, S., Kawasaki, K. and Miyoshi, T. (2012) Outcome of Pregnancy and Effects on the Right Heart in Women with Repaired Tetralogy of Fallot. Circulation Journal, 76, 957-963.

https://doi.org/10.1253/circj.CJ-11-1239

[16] Ramage, K., Grabowska, K., Silversides, C., Quan, H. and Metcalfe, A. (2019) Association of Adult Congenital Heart Disease with Pregnancy, Maternal, and Neonatal Outcomes. JAMA Network Open, 2, e193667.

https://doi.org/10.1001/jamanetworkopen.2019.3667

[17] Karamlou, T., Diggs, B.S., McCrindle, B.W. and Welke, K.F. (2011) A Growing Problem: Maternal Death and Peripartum Complications Are Higher in Women with Grown-Up Congenital Heart Disease. The Annals of Thoracic Surgery, 92, 2193-2198. https://doi.org/10.1016/j.athoracsur.2011.05.088

[18] Pillutla, P., Nguyen, T., Markovic, D., Canobbio, M., Koos, B.J. and Aboulhosn, J.A. (2016) Cardiovascular and Neonatal Outcomes in Pregnant Women with High-Risk Congenital Heart Disease. American Journal of Cardiology, 117, 1672-1677. https://doi.org/10.1016/j.amjcard.2016.02.045

[19] Yadav, V., Sharma, J.B., Mishra, S., Kriplani, A., Bhatla, N. and Kachhawa, G. (2018) Maternal and Fetal Outcome in Operated vs Non-Operated Cases of Congenital Heart Disease Cases in Pregnancy. Indian Heart Journal, 70, 82-86. https://doi.org/10.1016/j.ihj.2017.10.017

[20] Schlichting, L.E., Insaf, T.Z., Zaidi, A.N., Lui, G.K. and Van Zutphen, A.R. (2019) Maternal Comorbidities and Complications of Delivery in Pregnant Women with Congenital Heart Disease. Journal of the American College of Cardiology, 73, 2181-2191. https://doi.org/10.1016/j.jacc.2019.01.069

[21] Cauldwell, M., Von Klemperer, K., Uebing, A., Swan, L., Steer, P.J. and Gatzoulis, M. (2016) Why Is Post-Partum Haemorrhage More Common in Women with Congenital Heart Disease? International Journal of Cardiology, 218, 285-290. https://doi.org/10.1016/j.ijcard.2016.05.068

[22] Ladouceur, M., Benoit, L., Radojevic, J., Basquin, A., Dauphin, C. and Hascoet, S. (2017) Pregnancy Outcomes in Patients with Pulmonary Arterial Hypertension Associated with Congenital Heart Disease. Heart, 103, 287-292.

https://doi.org/10.1136/heartjnl-2016-310003

[23] Silversides, C.K., Grewal, J., Mason, J., Sermer, M., Kiess, M. and Rychel, V. (2018) Pregnancy Outcomes in Women with Heart Disease: The CARPREG II Study. Journal of the American College of Cardiology, 71, 2419-2430.

https://doi.org/10.1016/j.jacc.2018.02.076 
[24] Assenza, G.E., Cassater, D., Landzberg, M., Geva, T., Schreier, J. and Graham, D. (2013) The Effects of Pregnancy on Right Ventricular Remodeling in Women with Repaired Tetralogy of Fallot. International Journal of Cardiology, 168, 1847-1852. https://doi.org/10.1016/j.ijcard.2012.12.071

[25] Bowater, S.E., Selman, T.J., Hudsmith, L.E., Clift, P.F., Thompson, P.J. and Thorne, S.A. (2013) Long-Term Outcome Following Pregnancy in Women with a Systemic Right Ventricle: Is the Deterioration Due to Pregnancy or a Consequence of Time? Congenital Heart Disease, 8, 302-307. https://doi.org/10.1111/chd.12001

[26] Balint, O.H., Siu, S.C., Mason, J., Grewal, J., Wald, R. and Oechslin, E.N. (2010) Cardiac Outcomes after Pregnancy in Women with Congenital Heart Disease. Heart, 96, 1656-1661. https://doi.org/10.1136/hrt.2010.202838

[27] Kampman, M.A., Balci, A., Groen, H., van Dijk, A.P., Roos-Hesselink, J.W. and van Melle, J.P. (2015) Cardiac Function and Cardiac Events 1-Year Postpartum in Women with Congenital Heart Disease. American Heart Journal, 169, 298-304. https://doi.org/10.1016/j.ahj.2014.11.010

[28] Wacker-Gussmann, A., Thriemer, M., Yigitbasi, M., Berger, F. and Nagdyman, N. (2013) Women with Congenital Heart Disease: Long-Term Outcomes after Pregnancy. Clinical Research in Cardiology, 102, 215-222. https://doi.org/10.1007/s00392-012-0522-5 